\title{
AtOZF1 Positively Regulates Defense Against Bacterial Pathogens and NPR1-Independent Salicylic Acid Signaling
}

\author{
Nidhi Singh, Swadhin Swain, Anupriya Singh, and Ashis Kumar Nandi \\ School of Life Sciences, Jawaharlal Nehru University, New Delhi 110067, India \\ Accepted 6 November 2017.
}

\begin{abstract}
Plant hormone salicylic acid (SA) plays critical roles in defense signaling against biotrophic pathogens. Pathogen inoculation leads to SA accumulation in plants. SA activates a transactivator protein NPR1, which, in turn, transcriptionally activates many defense response genes. Reports also suggest the presence of NPR1-independent pathways for SA signaling in Arabidopsis. Here, we report the characterization of a zinc-finger proteincoding gene AtOZF1 that positively influences NPR1-independent SA signaling. Mutants of $A t O Z F 1$ are compromised, whereas AtOZF 1-overexpressing plants are hyperactive for defense against virulent and avirulent pathogens. AtOZF1 expression is $\mathrm{SA}$-inducible. AtOZF1 function is not required for pathogenesisassociated biosynthesis and accumulation of SA. However, it is required for SA responsiveness. By generating atozf1nprl double mutant, we show that contributions of these two genes are additive in terms of defense. We identified AtOZF1-interacting proteins by a yeast-two-hybrid screening of an Arabidopsis cDNA library. VDAC2 and NHL3 are two AtOZF1-interacting proteins, which are positive regulators of basal defense. AtOZF1 interacts with NHL3 and VDAC2 in plasma membrane and mitochondria, respectively. Our results demonstrate that AtOZF1 coordinates multiple steps of plant-pathogen interaction.
\end{abstract}

Plants possess a highly complex and well-elaborated immune system to combat diverse groups of pathogens they encounter. Recognition of microbe- or pathogen-associated molecular pattern genes through plant pattern recognition receptors (PRR) triggers a basal level defense (pattern-triggered immunity [PTI]) in plants (Li et al. 2016; Macho and Zipfel 2014). Successful pathogens release effector molecules to subdue PTI (Boller and He 2009; da Cunha et al. 2006; Jones and Dangl 2006). Recognition of these effectors by host cells activates effector-triggered immunity (ETI) (Boller and He 2009; Godiard et al. 1994; Jones and Dangl 2006; Nimchuk et al. 2003). Defense responses induced by PTI include activation of mitogen-activated protein kinases and transcription factors, production of reactive oxygen species (ROS),

Current address for Swadhin Swain: Department of Microbiology and Plant Biology, The University of Oklahoma, Norman, OK 73019, U.S.A.

${ }^{\dagger}$ Corresponding author: Ashis Kumar Nandi;

E-mail: ashis_nandi@mail.jnu.ac.in and ashis_nandi@yahoo.com

*The $\boldsymbol{e}$-Xtra logo stands for "electronic extra" and indicates that four supplementary figures and two supplementary tables are published online.

() 2018 The American Phytopathological Society enhanced accumulation of plant hormones like salicylic acid (SA), ethylene, and jasmonic acid, and induced expression of pathogenesisrelated $(P R)$ genes (Bigeard et al. 2015; Cohn et al. 2001; Nürnberger and Scheel 2001; Tsuda and Katagiri 2010). Activation of ETI induces similar but much higher-level responses than PTI. In addition, ETI is often associated with rapid programmed cell death surrounding the infection site, known as hypersensitive response (HR) (Morel and Dangl 1997). HR restricts the spread of the pathogen and serves as a signal for defense in the distal tissues to activate systemic acquired resistance (SAR) (Alvarez et al. 1998; da Cunha et al. 2006). However, HR is not a prerequisite for SAR activation, as virulent pathogen inoculation also activates SAR (Liu et al. 2011).

Plant hormone SA plays the most significant role in defense against biotrophic pathogens such as bacteria and oomycetes. SA and its glycoside (SAG) accumulate at an elevated level in the inoculated tissue as well as in pathogen-free distal tissue. The mutants of Arabidopsis that are defective in one or both SA biosynthesis and accumulation show impaired resistance against biotrophic pathogens (Giri et al. 2014, 2017; Glazebrook et al. 1996; Nandi et al. 2004; Roetschi et al. 2001; Singh et al. 2013; Wildermuth et al. 2001; Zhou et al. 1998). NONEXPRESSOR OF PR 1 (NPR1) protein is the master regulator of SA signaling (Dong 2004; Yan and Dong 2014). The mutants of NPR1 are defective both in local resistance and SAR. NPR1, which predominantly localizes in the cytoplasm of the resting cells, moves to the nucleus upon pathogen infection or exogenous SA application (Mou et al. 2003). In the nucleus, NPR1 increases binding of the TGA class of transcription factors to induce expression of $P R$ genes (Kesarwani et al. 2007; Saleh et al. 2015; Zhang et al. 1999). Though the NPR1 pathway remained as the primary SA signal transduction pathway in Arabidopsis, experiments suggest the existence of NPR1-independent pathways. Several nprl suppressor mutants such as suppressor of nprl-1, constitutive 1 (sncl), suppressor of SA insensitivity (ssil, ssi2), and constitutive defense without defect in growth and developmentl(cddl) constitutively activate SA accumulation and signaling in nprl mutant background (Li et al. 2001; Nandi et al. 2005; Shah et al. 1999, 2001; Swain et al. 2011). These mutants developmentally accumulate high levels of SA and are constitutive for SA signaling. A report indicated the role of TGA2 in NPR1-independent transcription of glutaredoxin GRXC9 in Arabidopsis (Herrera-Vásquez et al. 2015). However, a NPR1independent pathway for SA signaling in plants mostly remained elusive.

We reported earlier that mutant of At $2 g 19810$ show enhanced susceptibility to Pseudomonas syringae pv. tomato DC3000 (Swain et al. 2015). At2g19810 codes for the Arabidopsis thaliana OXIDATION-RELATED ZINC FINGER 1 (AtOZF1) 
protein, which is required for oxidative stress tolerance (Huang et al. 2011). AtOZF1 is a member of the conserved tandem $\mathrm{CCCH}$ zinc finger (TZF) family that contains three $\mathrm{CCCH}$-type zinc-finger domains (Bogamuwa and Jang 2014; Jang 2016; Wang et al. 2008). AtOZF1 expression increases upon $\mathrm{H}_{2} \mathrm{O}_{2}$ treatment (Dong 2004). Mutants of AtOZF1 show a severe reduction in primary root elongation and seedling growth, upon exogenous $\mathrm{H}_{2} \mathrm{O}_{2}$ application, compared with wild-type (WT) plants (Huang et al. 2011). In addition, AtOZF1 (also known as Arabidopsis thaliana ZINC-FINGER PROTEIN AtC3H2O/$A t T Z F 2$ ) expression is increased by multiple abiotic stresses, such as abscisic acid (ABA), salt, mannitol, and cold (Lee et al. 2012). Overexpression of AtOZF1/AtTZF2 enhances resistance to exogenous $\mathrm{H}_{2} \mathrm{O}_{2}$ application and drought in Arabidopsis (Lee et al. 2012). We report here that AtOZF1 is a positive regulator for defense against both virulent and avirulent pathogens. Our results also show that AtOZF1 takes part in NPR1-independent mechanisms of SA signaling.

\section{RESULTS}

AtOZF1 positively modulates defense against virulent and avirulent bacterial pathogens.

A mutant of AtOZF1 showed reduced resistance against P. syringae pv. tomato DC3000 (Swain et al. 2015). For further support, we used additional allelic T-DNA mutants and AtOZF1overexpressing plants and tested against virulent and avirulent pathogens. We obtained two T-DNA insertion mutant alleles of AtOZF1 (Salk_151571, atozf1-1; CS810235, atozfl-2) and confirmed $T$-DNA insertions by polymerase chain reaction (PCR) in
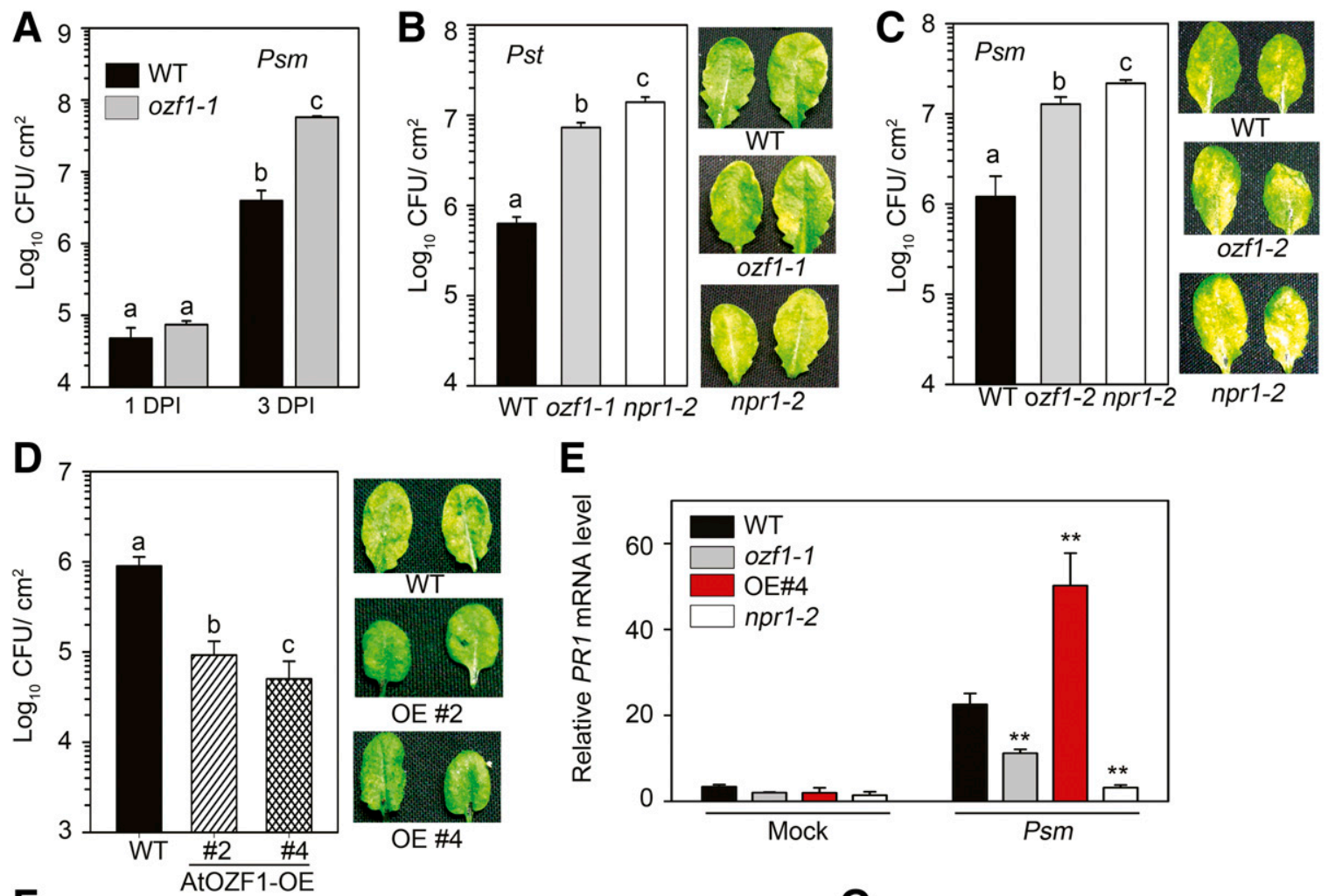

$\mathbf{F}$
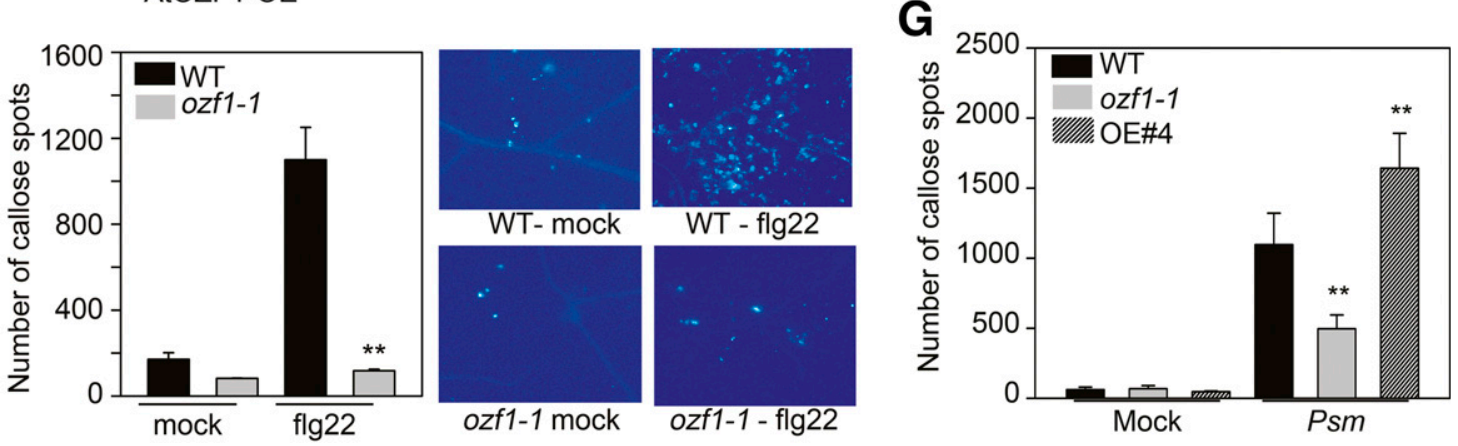

Fig. 1. Influence of AtOZF1 in defense against virulent pathogens. A, Pseudomonas syringae pv. maculicola (Psm) counts in wild type (WT) and atozf1-1 (ozf1-1) plants. B, P. syringae pv. tomato (Pst) counts and disease symptoms in WT, atozfl-1, and nprl-2 plants at 3 days postinoculation (dpi). C, P. syringae pv. maculicola counts and disease symptoms in WT, atozf1-2 (ozf1-2), and npr1-2 plants at 3 dpi. D, $P$. syringae pv. maculicola counts and disease symptoms in WT, atozf1-2, and two different AtOZF1 overexpressor (OE) lines at 3 dpi. In A to D, each bar represents the mean \pm standard deviation (SD) of four leaf samples, each carrying five leaf discs of $7 \mathrm{~mm}$ in diameter. Different letters above the bars indicate values that are significantly different $(P \leq 0.05)$ from each other, as analyzed by one-way analysis of variance (Holm-Sidak method). E, Relative abundance of PR1 transcript $48 \mathrm{~h}$ after $P$. syringae pv. maculicola inoculation. Each bar indicates mean $\pm \mathrm{SD}(n=3)$. F, Callose deposition after $10 \mathrm{~h}$ of flg 22 treatment. Each bar represents mean $\pm \mathrm{SD}(n=10)$. Representative microscope pictures are shown on the right. G, Callose deposition after $9 \mathrm{~h}$ of mock or P. syringae pv. maculicola inoculation. Each bar represents mean \pm SD of 10 samples. In all except $\mathrm{F}$, overnight-grown bacterial suspension at $5 \times 10^{5} \mathrm{CFU} / \mathrm{ml}$ in $10 \mathrm{mM} \mathrm{MgCl} \mathrm{Mas}_{2}$ wressure infiltrated. In $\mathrm{E}$, $\mathrm{F}$, and $\mathrm{G}$, one or two asterisks $(*)$ indicate the values that are significantly different from the corresponding samples of WT plants as determined by $t$ test $(P \leq 0.05$ and $P \leq 0.001$, respectively). Each experiment was repeated at least two times with similar results. 
these plants (Supplementary Fig. S1A). We monitored growth of two virulent strains of bacteria, $P$. syringae pv. tomato and $P$. syringae pv. maculicola ES4326 on WT and atozflmutant plants. In several experiments, we also included the nprl-2 mutant as control. We observed that mutants of AtOZF1 supported more bacterial load than WT plants (Fig. 1A to C). Susceptibility of atozfl mutants were almost similar to that of the npr 1-2 mutant (Fig. 1B and C). To further ascertain the influence of AtOZF1 in defense, we generated AtOZF1-overexpressing plants. Plants overexpressing AtOZF1 were significantly more resistant than WT plants against $P$. syringae pv. maculicola (Fig. 1D). In agreement with the defense against bacterial pathogens, atozfl expressed the PR1 gene at a lower level, whereas AtOZF1overexpressing lines were expressed at higher levels than WT plants (Fig. 1E). The atozf1-1 mutants also expressed other SAinducible genes, such as $P R 2$ and $P R 5$, at a lower level than WT plants (Supplementary Fig. S2). Resistance against bacterial pathogens is associated with callose, a mixture of $\beta-1,3$-glucans, deposition in the infected tissue (Dong et al. 2008). In agreement with the positive regulatory role of AtOZF1 in basal immunity, the atozfl-1 plants showed reduced callose deposition than WT plants upon treatment with flg22, an elicitor of PTI response in Arabidopsis (Fig. 1F). The atozfl mutants also showed reduced callose deposition after $P$. syringae $\mathrm{pv}$. maculicola inoculation, whereas it was enhanced in the AtOZF1 overexpressing plants (Fig. 1G). The above results suggest that AtOZF1 is essential for defense against virulent pathogens in Arabidopsis.

To get more insight about the role of AtOZF1 in plant defense, we examined the defense response against avirulent bacterial pathogens such as $P$. syringae pv. tomato carrying AvrRpt2 (Pst-AvrRpt2) or AvrB (Pst-AvrB) genes. As observed for virulent pathogens, against avirulent pathogens, also, atozfl mutants showed higher susceptibility than WT plants. Bacterial titers in atozf1-1 plants were much higher than WT plants and were similar to nprl-2 plants (Fig. 2A and B). Moreover, plants overexpressing AtOZF1 showed a significant reduction in bacterial load compared with WT and atozfl-1 plants (Fig. 2C), suggesting AtOZF1 is necessary to mount a resistance against avirulent pathogens. High-level infection with an avirulent pathogen results in an apoplastic oxidative burst, invoking production of higher amounts of ROS in the leaves. The ROS inhibit future growth of the pathogen by creating a highly oxidizing environment, which also activates death of surrounding plant cells, called the hypersensitive response (HR). To determine the role of AtOZF1 in ROS accumulation, we performed diaminobenzidine (DAB) staining in WT and atozfl-1 after PstAvrRpt 2 infection. The atozfl-1 leaves showed significantly reduced DAB staining compared with the WT leaves (Fig. 2D), suggesting that AtOZF1 is essential for normal oxidative burst upon avirulent pathogen infection. The cells undergoing HR release ionic contents to the apoplast. Such tissues, when floated in distilled water, release ions and thereby increase the electrical conductivity of water, which quantitatively reflects the level of cell death. The atozfl-1 mutant shows a significantly lower level of ion leakage compared with WT plants upon Pst-AvrRpt2 inoculation (Fig. 2E), suggesting a role of AtOZF1 that is important for HR induction. Altogether, these results indicate that AtOZF1 positively influences defense against virulent and avirulent bacterial pathogens.
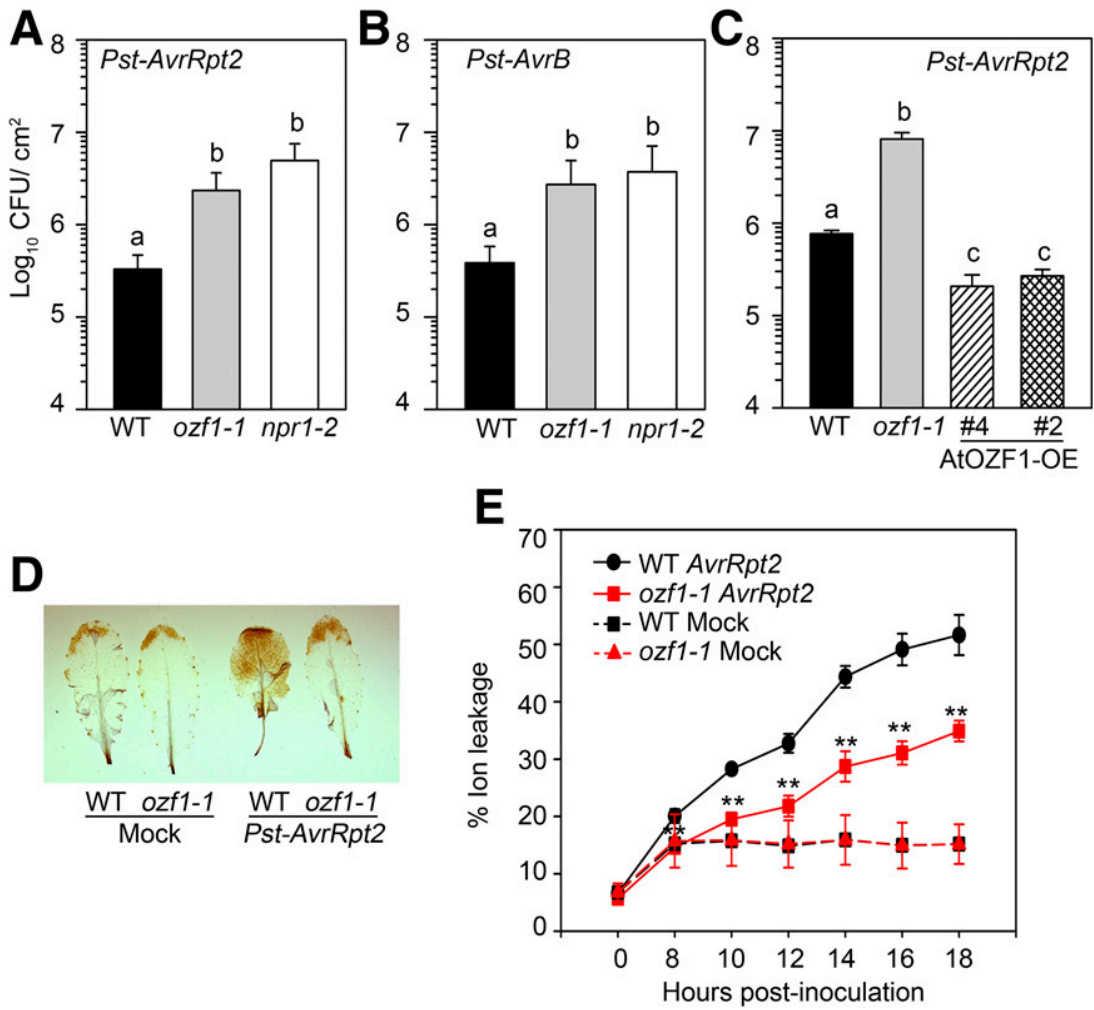

Fig. 2. Influence of AtOZF1 in defense against avirulent pathogens. A, Pst-AvrRpt2 counts in wild type (WT), atozf1-1, and $n p r 1-2$ plants. B, Pst-AvrB counts in WT, atozf1-1, and nprl-2 plants. C, Pst-AvrRpt 2 counts in WT and AtOZF1 overexpressor (OE) plants. Bacterial culture suspended at $1 \times 10^{6} \mathrm{CFU} / \mathrm{ml}$ in $10 \mathrm{mM} \mathrm{MgCl}{ }_{2}$ was pressure-infiltrated, and bacterial load was counted at 3 days postinoculation. Each bar represents the mean \pm standard deviation (SD) of four leaf samples, each carrying five leaf discs of $7 \mathrm{~mm}$ in diameter. Different letters above the bars indicate values that are significantly different $(P \leq 0.05)$ from each other, as analyzed by one-way analysis of variance (Holm-Sidak method). D, Diaminobenzidine staining for $\mathrm{H}_{2} \mathrm{O}_{2}$ detection after $3 \mathrm{~h}$ of floating in water containing Pst-AvrRpt 2 at $10^{8} \mathrm{CFU} / \mathrm{ml}$. E, Electrolyte leakage from Pst-AvrRpt2-inoculated leaves of WT and atozfl-1. Each point represents mean \pm SD $(n=3)$ Two asterisks $(* *)$ indicate values from atozfl-1 that are significantly different $(P \leq 0.001)$ from WT, as obtained through $t$ test for that specific timepoint. Each experiment was repeated at least two times with similar results. 


\section{AtOZF1 is not required}

\section{for pathogen-induced SA accumulation.}

Immune response against hemibiotrophic pathogens like bacteria is mediated by defense hormone SA (Delaney et al. 1994). Pathogen infection activates SA signaling by enhancing accumulation of endogenous SA and SAG. Since AtOZF1 positively modulates defense response and pathogen-induced PRl-transcript accumulation (Figs. 1 and 2), we speculated its influence in pathogen-induced SA accumulation. To investigate this possibility, we measured basal and pathogen-induced accumulation of SA in WT, atozf1-1, and AtOZF 1-overexpressing plants. High-pressure liquid chromatography (HPLC) analysis for SA accumulation in $P$. syringae pv. maculicola or mockinoculated leaves suggested that AtOZF1 had not much influence on pathogenesis-associated SA biosynthesis pathway or accumulation in Arabidopsis (Fig. 3A and B). Disruption of AtOZF1 expression did not affect basal SA accumulation in mock-treated plants. There was only a small reduction in total SA level in $P$. syringae pv. maculicola-inoculated leaves of atozfl-1 compared with the WT plants (Fig. 3A). We did not observe any increase of pathogen-induced total SA level in the AtOZF1-overexpressing plants; however, we observed a slight increase in free SA content in some of our experiments (Fig. $3 \mathrm{~B})$. From these results, we conclude that AtOZF1 function is not significantly required for pathogen-induced SA accumulation but may, however, positively influence free-SA levels when overexpressed.
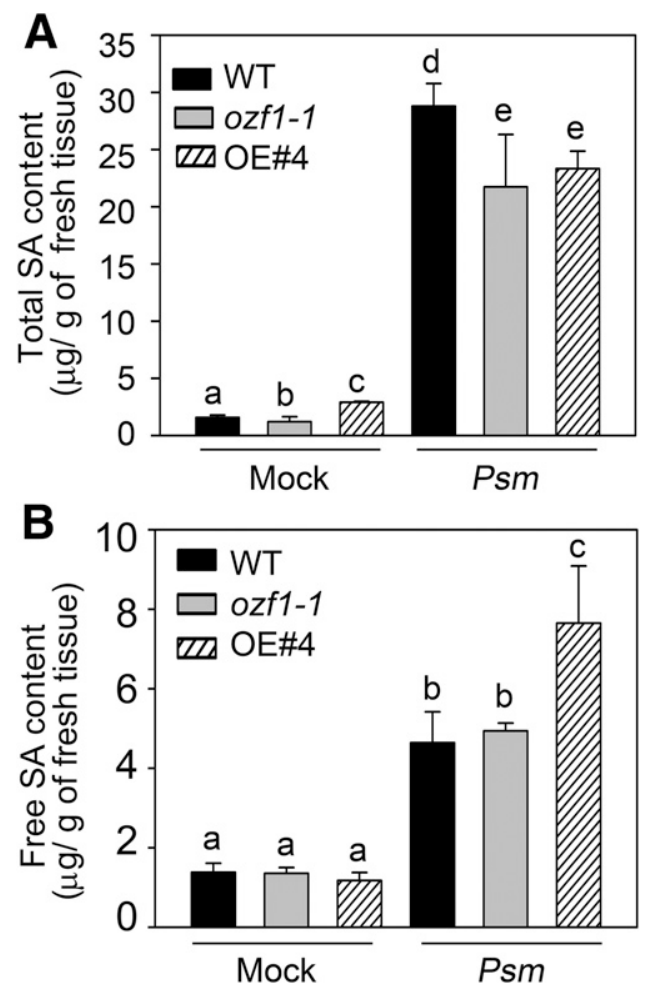

Fig. 3. Salicylic acid (SA) content in wild type (WT), atozf1-1, and AtOZF1 overexpressing plants. A, Total SA (SA+SAG) content in mock or Pseudomonas syringae pv. maculicola (Psm)-inoculated WT, atozf1-1, and AtOZF1 overexpressor (OE) plants. B, Free SA content in mock or P. syringae pv. maculicola-inoculated WT, atozfl-1, and AtOZF1-OE plants. Plants were inoculated with either $P$. syringae pv. maculicola at $5 \times$ $10^{5} \mathrm{CFU} / \mathrm{ml}$ suspended in $10 \mathrm{mM} \mathrm{MgCl}{ }_{2}$ or only $10 \mathrm{mM} \mathrm{MgCl} 2$ as mock control. Samples were harvested 2 days after inoculation. Each bar represents mean \pm standard deviation of five samples. Different letters above the bars indicate values that are significantly different $(P \leq 0.05)$ from each other, as analyzed by one-way analysis of variance (Holm-Sidak method). Experiments were repeated two times with similar results.
AtOZF1 is essential for SA sensitivity and positively regulates NPR1-independent defense responses.

AtOZF1 positively regulates defense and PRI expression without impacting SA accumulation. It is most likely possible that AtOZF1 functions as a positive regulator of SA signaling downstream of SA accumulation. To support such a hypothesis, we examined the effect of exogenous SA application on disease resistance and PRl transcript accumulation in WT, atozfl-1, and nprl-2 plants. Five-week-old soil-grown plants were sprayed with water $(0 \mu \mathrm{M} \mathrm{SA})$ or SA $(50,100$ or $150 \mu \mathrm{M})$ and, $24 \mathrm{~h}$ later, all plants were inoculated with $P$. syringae pv. maculicola. Bacterial counts at 3 days postinoculation (dpi) showed that SA application in WT plants significantly reduced bacterial load, whereas it had little effect on nprl-2 mutant plants (Fig. 4A). Interestingly, compared with WT plants, the atozf $1-1$ plants were less-responsive to exogenous SA when applied at a low concentration $(50 \mu \mathrm{M})$. To compare, we calculated fold protection by SA treatment as a ratio of mean CFU in water-treated plants to that of SA-treated plants. The results showed that in the low concentration of SA $(50 \mu \mathrm{M})$, fold protection in WT plants is much higher than atozfl-1 plants (Fig. 4B). A similar reduced SA sensitivity in atozfl-1 plants was also observed in terms of $P R 1$ expression. Exogenous SA application significantly enhanced $P R I$ transcript accumulation in WT plants but not in nprl-2 plants (Fig. 4C). The atozfl-1 plants were not defective in PRI expression but were less responsive than WT plants toward exogenous SA treatment at higher concentrations (100 and $150 \mu \mathrm{M})$ (Fig. 4C). Together, these results suggest that $A t O Z F 1$ is required for the normal level of SA sensitivity of Arabidopsis.

To see the interrelationship of AtOZF1 and NPR1 in defense signaling, we generated double mutant atozfl-1 nprl-2. We observed that the double mutant showed additive susceptibility of each of the single mutants toward both virulent pathogen P. syringae pv. maculicola (Fig. 4D) and avirulent pathogen PstAvrRpt2 (Fig. 4E). This additive property was also observed in terms of pathogen-induced $P R I$ expression. Pathogen-induced $P R 1$ expression was lower in atozfl-1 and nprl-2 than WT plants. Moreover, the atozfl-1 nprl-2 double mutant expressed $P R 1$ at a lower level than each single mutant (Fig. 4F). Together these results demonstrated that AtOZF1 and NPR1 function additively in defense signaling, suggesting a NPR1-independent role for AtOZF1in SA signaling.

\section{AtOZF1 expression is SA-inducible.}

The results described above demonstrated that AtOZF1 influences SA response and SA-mediated signaling. To investigate whether AtOZF1 expression is SA-regulated, we monitored $A t O Z F 1$ mRNA accumulation after spraying SA on WT plants. Northern blot hybridization showed enhanced accumulation of AtOZF1 mRNA in plants treated with $500 \mu \mathrm{M}$ of SA (Fig. 5A). Spraying plants with different concentrations of SA showed that AtOZF1 mRNA accumulation was enhanced with increasing concentrations of SA (Fig. 5B). Results suggest that $A t O Z F 1$ expression is transcriptionally controlled by SA.

\section{AtOZF1 interacts with VDAC2 and NHL3.}

To reveal the possible mechanism of AtOZF1-mediated plant defense, we looked for its interacting partners. Using AtOZF1 as bait in a yeast-two-hybrid assay, we screened an Arabidopsis cDNA library and obtained a total of 25 interacting clones. Sequencing of the plasmids identified 24 different cDNA-containing clones (Supplementary Table S1, At5g10360 appeared in two clones). Among the interacting proteins, NDR1/HIN1-LIKE 3 (NHL3, coded by At5g06320) was the only previously known modulator of plant defense (Varet et al. 2002, 2003). Besides 
NHL3, we also selected VOLTAGE-DEPENDENT ANION CHANNEL 2 (VDAC2, coded by At5g67500) for further analysis. Nicotiana benthamiana VDAC2 (NbVDAC2) promotes nonhost resistance and pathogenesis-induced $\mathrm{H}_{2} \mathrm{O}_{2}$ production (Tateda et al. 2009). Expression of Arabidopsis VDAC2 increases upon virulent and avirulent pathogen inoculation (Tateda et al. 2011). Members of the Arabidopsis VDAC family, such as AtVDAC1, influence resistance against avirulent pathogen PstAvrRpt2 (Tateda et al. 2011). To determine the part of AtOZF1 protein that is required for interaction with NHL3 and VDAC2, we performed yeast-two-hybrid interaction with a series of truncated AtOZF1 protein (Fig. 6A). We used AtOZF1, VDAC2, and NHL3, individually, along with corresponding empty vectors as negative controls (Supplementary Fig. S3). We found $d 6$, having only the $\mathrm{C}$-terminal 142 amino acids without any zincfinger, was the smallest fragment that strongly interacts with VDAC2 (Fig. 6B) The other fragments, like $d 5, d 2$, and fulllength AtOZF1, interact with VDAC2 but in a lower efficiency than the $d 6$ fragment. It is possible that the other domains function as autoinhibitory for the interaction. Alternatively, certain yeast proteins may interact and cause a steric hindrance in the larger AtOZF1 proteins. Unlike VDAC2, we did not find the interaction of $d 6$ with NHL3. The smallest fragment that interacted with NHL3 was $d 5$, which contains the C-terminal 180 amino acids along with the third zinc-finger (Fig. 6B). However, similar to VDAC2, the interaction weakened in the larger AtOZF1 fragments (Fig. 6B).

In planta interaction of AtOZF1 with VDAC2 and NHL3 was confirmed by a bimolecular fluorescence complementation (BiFC) assay. AtOZF1 and NHL3 coding sequences were transcriptionally fused with $\mathrm{N}$ - and $\mathrm{C}$-terminal halves of yellow fluorescent protein (YFP) present in pSPYNE and pSPYCE, respectively (Waadt et al. 2008). Fusion proteins were transiently expressed in $N$. benthamiana. As a positive control, we used pGMAS-CIPK24 and pSPYNE-CBL1, which interact in the plasma membrane (Waadt et al. 2008) (Supplementary Fig. S4A). NHL3 was known to localize in the plasma membrane (Varet et al. 2003). We observed that NHL3 and AtOZF1 interact to generate a functional YFP and the fluorescence merges with FM64-red, a plasma membrane-binding dye (Fig. 6C). The results suggest the plasma membrane as the place of interaction for AtOZF1 and NHL3. Arabidopsis VDAC2-GFP (green fluorescent protein) localizes in the mitochondria and the cytoplasm (Tateda et al. 2011). Our BiFc analysis suggests that interaction of VDAC2 and AtOZF1 takes place predominantly in the mitochondria (Fig. 6C). Coexpression of only the N-terminal half of YFP-NHL3 or VDAC2 and empty vector pSPYCE failed to produce functional YFP, suggesting that interactions were required for YFP reconstitution. Further, to confirm the physical interaction of AtOZF1 with VDAC2 and
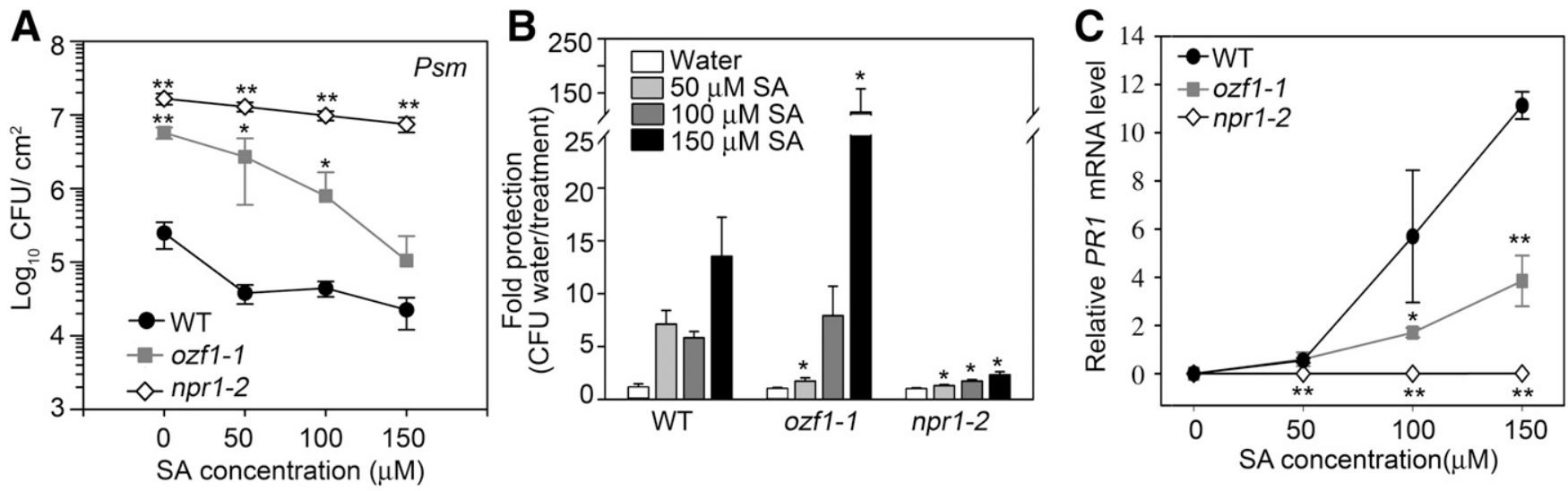

D

$\mathbf{E}$
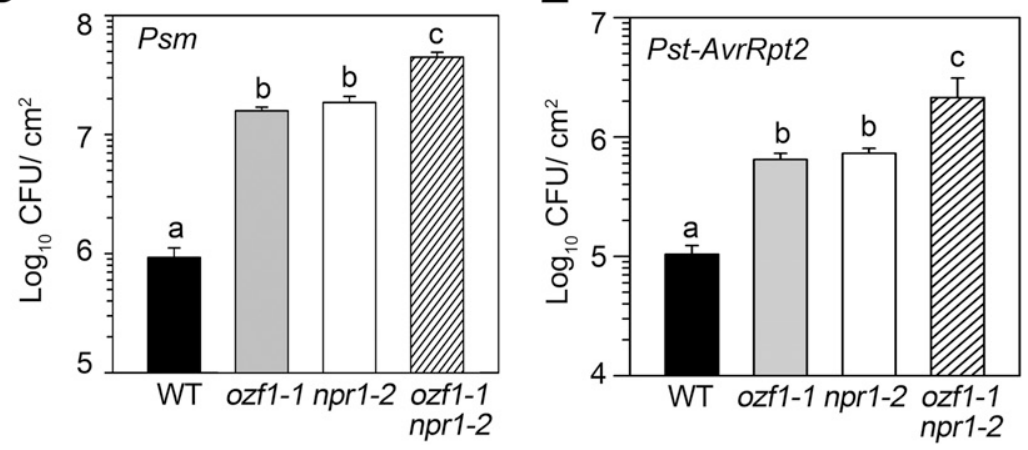

$\mathbf{F}$

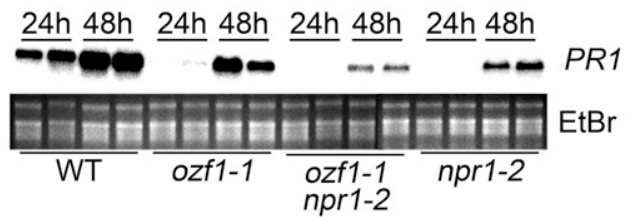

Fig. 4. Role of AtOZF1 in salicylic acid (SA) sensitivity and signaling. A, Pseudomonas syringae pv. maculicola (Psm) counts at 3 days postinoculation (dpi) in wild type (WT), atozfl-1, and nprl-2 plants after spraying with 0, 50, 100, or $150 \mu \mathrm{M}$ of SA. P. syringae pv. maculicola inoculation was done after $24 \mathrm{~h}$ of SA spray. B, Fold reduction in P. syringae pv. maculicola counts after SA spray, with respect to water-treated plants. The fold indicates the ratio of mean watertreated CFU counts to individual CFU counts for each sample. C, PRl transcript accumulation after $24 \mathrm{~h}$ of SA treatment in WT, atozfl-1, and nprl-2 plants. Each point in the line plot indicates mean \pm standard deviation (SD) $(n=3)$. One or two asterisks indicate the values in mutants that are significantly different from the corresponding samples of WT plants $(P \leq 0.05$ and $P \leq 0.001$, respectively). D, $P$. syringae pv. maculicola counts at 3 dpi in the indicated genotypic plants. E, Pst-AvrRpt 2 counts at $3 \mathrm{dpi}$ in the indicated genotypic plants. F, P. syringae pv. maculicola-induced PR1 transcript accumulation. Plants of the indicated genotypes were inoculated with $P$. syringae pv. maculicola and samples were harvested at 24 and $48 \mathrm{~h}$ postinoculation. Northern blot hybridization was done using PR1 cDNA as probe. Ethidium bromide (EtBr)-stained gel picture indicates relative amount of RNA loaded in the gel. In all experiments, pathogens were inoculated at $5 \times 10^{5} \mathrm{CFU} / \mathrm{ml}$. In A, D, and E, each bar or point in the line plot indicates mean \pm SD of four samples carrying five leaf-discs of $7 \mathrm{~mm}$ in diameter. Different letters above the bars indicate values that are significantly different $(P \leq 0.05)$ from each other, as analyzed by one-way analysis of variance (Holm-Sidak method). Experiments were repeated at least two times with similar results. 
NHL3, we performed coimmunoprecipitation (CoIP) followed by Western blot analysis. Transiently expressed AtOZF1Myc protein in $N$. benthamiana coimmunoprecipitated with VDAC2-HA (hemagglutinin) or NHL3-HA and vice versa (Fig. 6D; Supplementary Fig. S5A). Expression of AtOZF1 or its interacting factor alone served as required negative control. As a positive control of the experiment, we used CIPK24 and CBL1.

\section{VDAC2 and NHL3 are positive regulators} of basal defense.

Expression of NHL3 is induced by virulent and avirulent strains of $P$. syringae pv. tomato (Varet et al. 2002). Overexpression of NHL3 confers resistance against $P$. syringae pv. tomato DC3000 (Varet et al. 2003). The reports suggested NHL3 as a positive regulator of basal defense. To validate further, we used a T-DNA insertion mutant line of NHL3 (salk_150318) (Supplementary Fig. S6A and B) and challenged it with the virulent pathogen P. syringae pv. maculicola. As anticipated, we observed higher bacterial growth in the $n h l 3$ mutant compared with WT plants (Fig. 7A). To determine the role of VDAC2 in defense, we studied disease resistance in a T-DNA insertion mutant line of VDAC2 (CS818558). Similar to $n h l 3$, the vdac2 mutant also supported a higher bacterial proliferation than WT plants (Fig. 7A). However, the influence of AtOZF1 in defense was higher than both VDAC2 and NHL3. The mutants, along with WT and atozf1-1, were also challenged with the avirulent pathogen $P s t$ AvrRpt2. We did not find much difference regarding resistance against avirulent pathogen (Fig. 7B). The results suggest that VDAC2 and NHL3 are positive regulators of PTI-mediated basal defense.

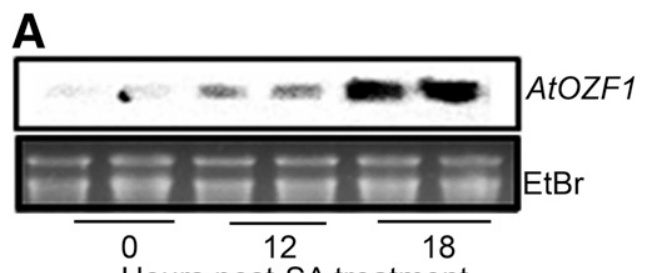

Hours post-SA treatment

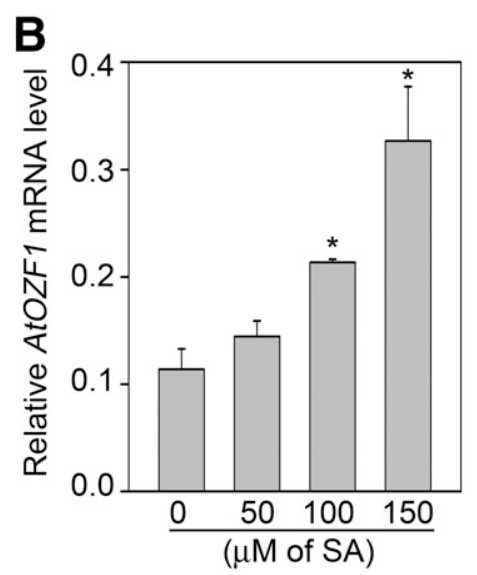

Fig. 5. AtOZF1 mRNA accumulation after salicylic acid (SA) treatment. A, SA-induced expression of AtOZF1 mRNA in wild-type (WT) plants, as determined by Northern blot hybridization. Plants were sprayed with $500 \mu \mathrm{M} \mathrm{SA}$ and samples were harvested after 0,12 , and $18 \mathrm{~h}$ of treatment. B, AtOZF1 expression after spraying SA at different concentrations. WT plants were sprayed with SA solution and samples were harvested $18 \mathrm{~h}$ after spraying. AtOZF1 transcript accumulation was determined by quantitative polymerase chain reaction. Each bar represents mean \pm standard deviation $(n=3)$. One or two asterisks (* or **) indicate values of $P \leq 0.05$ or $P \leq$ 0.001 , respectively, in the treatment compared with control $(0 \mathrm{~h}$ sample). Experiments were repeated two times with similar results.

\section{AtOZF1 is required}

for pathogen-induced $V D A C 2$ mRNA accumulation.

To study the pathogenesis-associated expression of VDAC2 and NHL3, we monitored their mRNA accumulation by quantitative (q)PCR after $P$. syringae pv. maculicola inoculation in WT plants. We also included atozfl-1 mutant in the study, to examine whether AtOZF1 influences their expression. As expected, we observed enhanced expression of both $V D A C 2$ and NHL3 in WT plants after $P$. syringae pv. maculicola inoculation (Fig. 7C and D). We did not observe much difference between WT and atozf $1-1$ in terms of NHL3 mRNA accumulation, suggesting that AtOZF1 function is not required for pathogen-induced expression of NHL3 (Fig. 7D). In contrast, accumulation of VDAC2 mRNA was significantly lower in atozf1-1 than in WT plants (Fig. 7C). Results suggest that AtOZF1 is essential for $V D A C 2$ expression under pathogen stress and the inability to induce $V D A C 2$ may partly be responsible for enhanced bacterial growth in $A t O Z F 1$ mutant plants.

\section{DISCUSSION}

This work and the previously published literature clearly demonstrated the significance of AtOZF1 as a positive regulator of defense responses against multiple abiotic and biotic stresses. AtOZF1 overexpression provides enhanced resistance to abiotic stresses and exogenous $\mathrm{H}_{2} \mathrm{O}_{2}$ application through yet unidentified mechanisms (Huang et al. 2011; Lee et al. 2012). Our results show that, on defense against pathogens, AtOZF1 coordinates multiple steps, including ROS accumulation, ETIinduced ion leakage, and SA signaling (Fig. 8A). Exogenous $\mathrm{SA}$ application induces AtOZF1 expression. Thus, AtOZF1 may be considered as an integral component of disease defense mechanism of Arabidopsis.

\section{Role of AtOZF1 in plant defense.}

AtOZF1 positively regulates defense against bacterial pathogens. Mutants of AtOZF1 are susceptible to both compatible and incompatible pathogens and express reduced level of $P R I$ transcript compared with WT plants. In contrast, plants overexpressing AtOZF1 are hyper-resistant compared with WT plants. Interestingly, the $A t O Z F 1$ overexpression does not make plants constitutive for defense. Most of the mutants or overexpression plants that constitutively activate defense are compromised for growth, developmentally accumulate SA, and develop spontaneous necrosis (Bolton 2009; Heidel et al. 2004; Huot et al. 2014; Jirage et al. 2001). In contrast, AtOZF 1 overexpressor plants do not accumulate a high level of SA without pathogen inoculation and do not express $P R$ genes constitutively. Morphology of overexpressor plants is also comparable to that of the WT plants. Thus, AtOZF1 may function as an enhancer of inducible plant defense in Arabidopsis.

AtOZF1 influences several aspects of plant defense. It promotes ROS accumulation, HR-mediated ion-leakage, SA signaling and bacterial growth. These events of defense response are interlinked but not necessarily follow synchronized regulation (Torres et al. 2005; Galletti et al. 2008; Yun et al. 2011; Chaouch et al. 2012). Arabidopsis respiratory burst oxidase homologs (RBO; NADPH oxidase), AtRbohD and AtRbohF contribute to ROS accumulation induced by both virulent and avirulent pathogens, but influence defense only against virulent pathogens (Torres et al. 2002; Chaouch et al. 2012). Since, AtOZF1 influences ROS accumulation, ion-leakage, defense against both virulent and avirulent pathogens, but does not influence SA accumulation, we presume two distinct nodes at which AtOZF1 interacts with defense signaling. In the first node, it influences ROS accumulation, ion-leakage and general defense against virulent pathogens (Fig. 8A). Functions at this 
node are similar to the earlier reported roles of AtOZF1, which include oxidative stress and ABA signaling (Huang et al. 2011; Lee et al. 2012). The role of AtOZF1 in ABA signaling may also be associated with its function in oxidative stress. Double mutant atrbohD/F is impaired in ABA-induced ROS production, stomatal closure and seed germination inhibition (Kwak et al. 2003). At the second node, AtOZF1influences SA signaling downstream to SA accumulation (Fig. 8B). AtOZF1 function at this node contributes to resistance against both virulent and avirulent pathogens and expression of $P R$ genes.

\section{Contribution of AtOZF1 in SA signaling.}

NPR1 is the most important regulator of SA signaling. Though the existence of NPR1-independent pathway is established, the machinery remained elusive. Many Arabidopsis mutants, for example, sncl, ssil and ssi2, and $c d d 1$, constitutively activate SA accumulation and signaling in the nprl mutant background (Li et al. 2001; Nandi et al. 2005; Shah et al. 1999, 2001; Swain et al. 2011). These genes are negative regulators of NPR1-independent signaling. Our results identified AtOZF1 as a positive regulator of defense that functions in a pathway that is parallel to NPR1. Effects of individual mutations in NPR1 or AtOZF1, in terms of restricting bacterial growth, are similar. The double mutants show an additive effect on bacterial growth and suppression of pathogen-induced $P R$ gene expression, which suggest a function parallel to NPR1 (Fig. 8B). However, exogenous SA application prior to pathogen inoculation, suggest the involvement of AtOZF1in both NPR1-dependent and -independent pathways. At lower concentration of SA, AtOZF1mutant fails to provide WT-level protection in the presence of the NPR1 gene. Thus, AtOZF1 has a NPR1-independent effect in restricting the growth of pathogens in response to exogenous SA application. Similarly, SA-induced expression of PRI is also influenced by AtOZF1, even in the presence of NPR1.
A

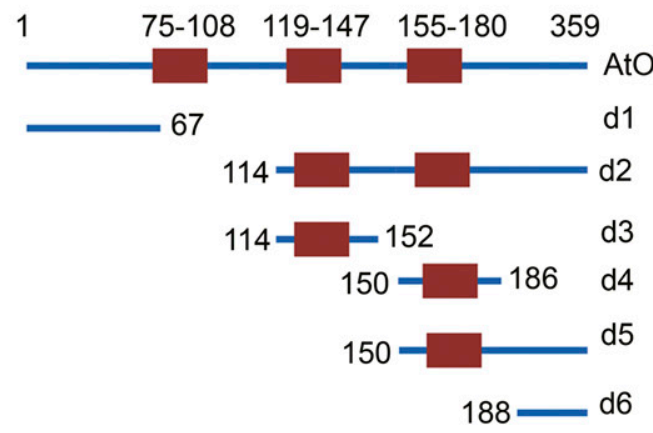

B

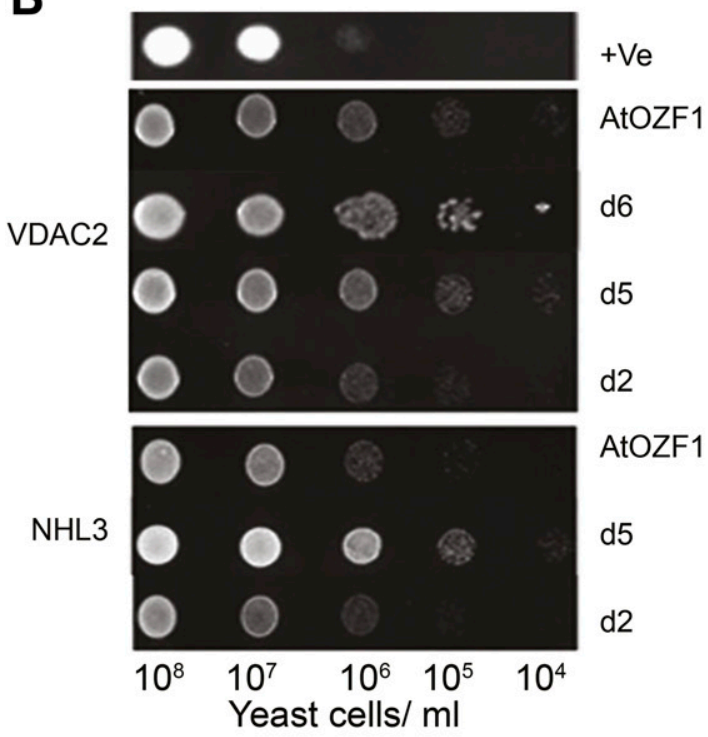

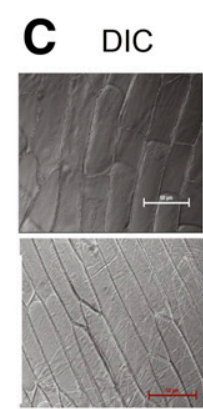

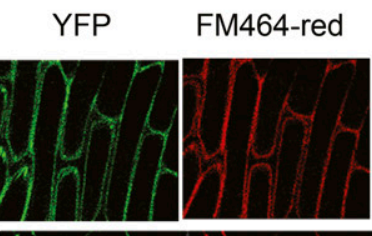

merge

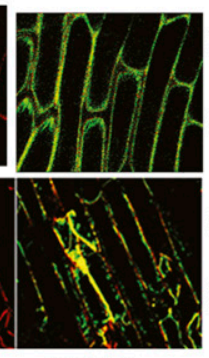

pSPYNE-NHL3

$+$

pSPYCE-AtOZF1

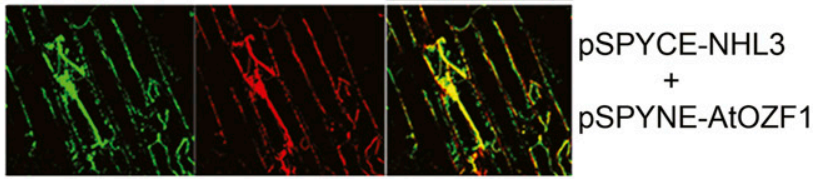

DIC

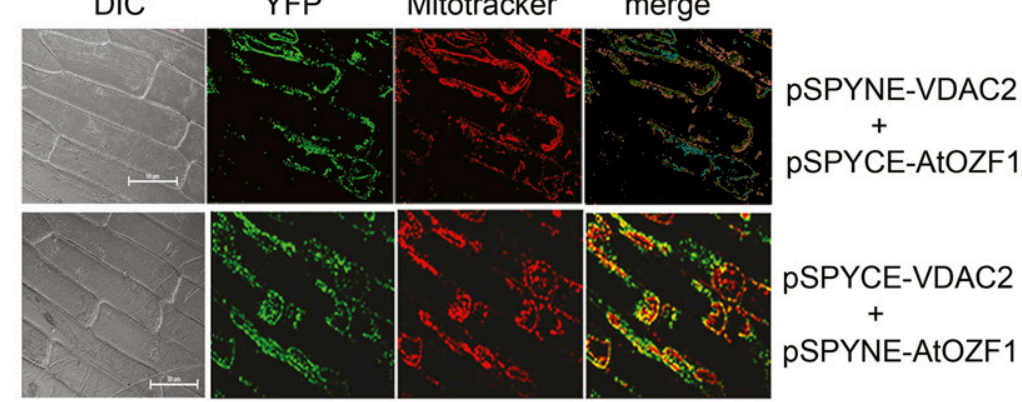

D

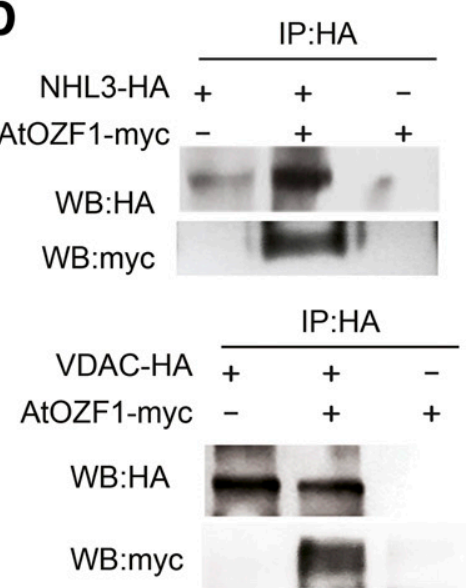

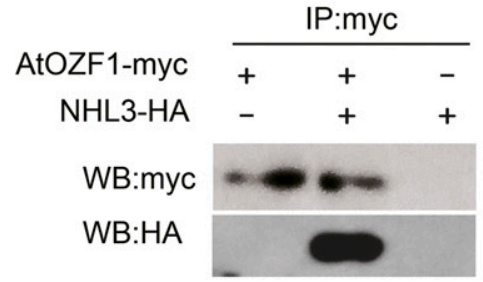

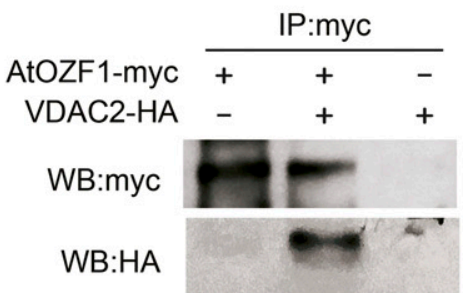

Fig. 6. Interaction of AtOZF1 with VDAC2 and NHL3. A, Schematic representation of full-length AtOZF1 protein and its deleted derivatives. Boxes indicate zinc-finger domains. Numbers indicate amino-acid positions from the $\mathrm{N}$-terminal end. B, Growth of yeast cells in Y2H selection medium. +Ve control cells contain pGBKT7-P53 and pGADT7-T antigen. VDAC2 or NHL3 was cloned in pGADT7. AtOZF1 and its deleted fragments were cloned in pGBKT7. Overnight-grown yeast cells were suspended at $10^{8}$ cells $/ \mathrm{ml}$ and serially diluted before spotting in the selection medium. All photographs were taken at the same magnification after two days of growth at $28^{\circ} \mathrm{C}$. C, BiFC assay to detect interaction of AtOZF1 with VDAC2 or NHL3 in onion cells. pSPYNE and pSPYCE vectors provide N and C terminals of YFP respectively. YFP and FM64-red or mitrotracker images were taken from the same observation field at the same magnification using a confocal microscope. D, Coimmunoprecipitation of AtOZF1-Myc and NHL3-HA or VDAC2-HA after transient expression in Nicotiana benthamiana leaves. 
However, since exogenous SA-induced $P R I$ expression is dependent on NPR1 (Fig. 4C), we believe that AtOZF1 functions as an enhancer of NPR1 in that pathway (Fig. 8C).

\section{Mechanism of AtOZF1-mediated defense.}

The biochemical function of AtOZF1 is not elucidated in detail. The protein contains three $\mathrm{CCCH}$-type zinc fingers. Several tandem-arrayed CCCH-type zinc-finger proteins are implicated in mRNA turnover (Lee et al. 2012; Kim et al. 2014; Qu et al. 2014). In an in vitro RNase activity assay, AtOZF1 has been shown to degrade several Arabidopsis RNA molecules (Lee et al. 2012). However, it is not known whether it is a general RNase activity or specific against certain RNA species. Besides RNase activity, tandem-CCCH zinc-finger domains also take part in protein-protein interaction (Guo et al. 2009). Cotton (Gossypium hirsutum) zinc-finger protein 1 (GhZFP1) contains two tandem-CCCH zinc-fingers. Screening of a cotton cDNA library with GhZFP1 identified two proteins, GZIRD21A (GhZFP1 interacting and responsive to dehydration protein 21A) and GZIPR5 (GhZFP1 interacting and pathogenesisrelated protein 5), which interact with GhZFP1. Yeast-twohybrid analysis with deleted domains of GhZFP1 suggests the part of the protein carrying zinc-finger domains assists in the interaction (Guo et al. 2009). We identified two AtOZF1 interactors, VDAC2 and NHL3, that positively influence defense against bacterial pathogens. VDACs are mitochondrial outer membrane-localized proteins that play roles in plant defense, cell death, and $\mathrm{H}_{2} \mathrm{O}_{2}$ production (Kusano et al. 2009). Our results show that VDAC2 function is required for resistance to virulent pathogens. VDAC 2 and NHL3 are localized in the mitochondria and the plasma membrane, respectively, and interact with AtOZF1 in their respective subcellular organelles. Since
AtOZF1 protein does not contain any specific subcellular localization signal, we believe that the interacting proteins influence its localization. Thus, it may be possible that VDAC2 and NHL3 by interacting with AtOZF1 in its C-terminal domain help in moving to mitochondria and plasma membrane, respectively (Fig. 8A). Our results show that AtOZF1 function is also required for pathogen-induced transcription of $V D A C 2$. Earlier, another tandem $\mathrm{CCCH}$ zinc-finger protein, $\mathrm{AtC} 3 \mathrm{H} 4$, is reported to bind single- and double- stranded DNA and RNA and to function as a transcriptional activator (Kim et al. 2014). Thus, we cannot rule out the possibility of AtOZF1 functioning as a transcriptional activator for plant defense.

In summary, our report illustrated the functional significance of the zinc-finger protein AtOZF1 in plant immune responses. The results revealed two crucial roles of AtOZF1. First, AtOZF1 functions downstream of SA accumulation and positively modulates NPR1-independent SA signaling. Second, it interacts with VDAC2 and NHL3, which were shown to promote basal defense against bacterial pathogens. Further investigations will uncover how these interactions help plants to fight against pathogens.

\section{MATERIALS AND METHODS}

\section{Plant materials and growth conditions.}

All Arabidopsis plants were of Col-0 ecotype. The T-DNA insertion mutants atozf1-1 (Salk_151571), atozf1-2 (CS810235), vdac2 (CS818558), and nhl3 (Salk_150318) were obtained from the Arabidopsis Biological Resource Center, Ohio State University, Columbus, OH, U.S.A. Allelic compositions were determined by standard PCR-based techniques. Primer sequences are mentioned in Supplementary Table S2. The double mutant atozfl-1nprl-2 was generated by crossing homozygous parental lines. The atozfl-1
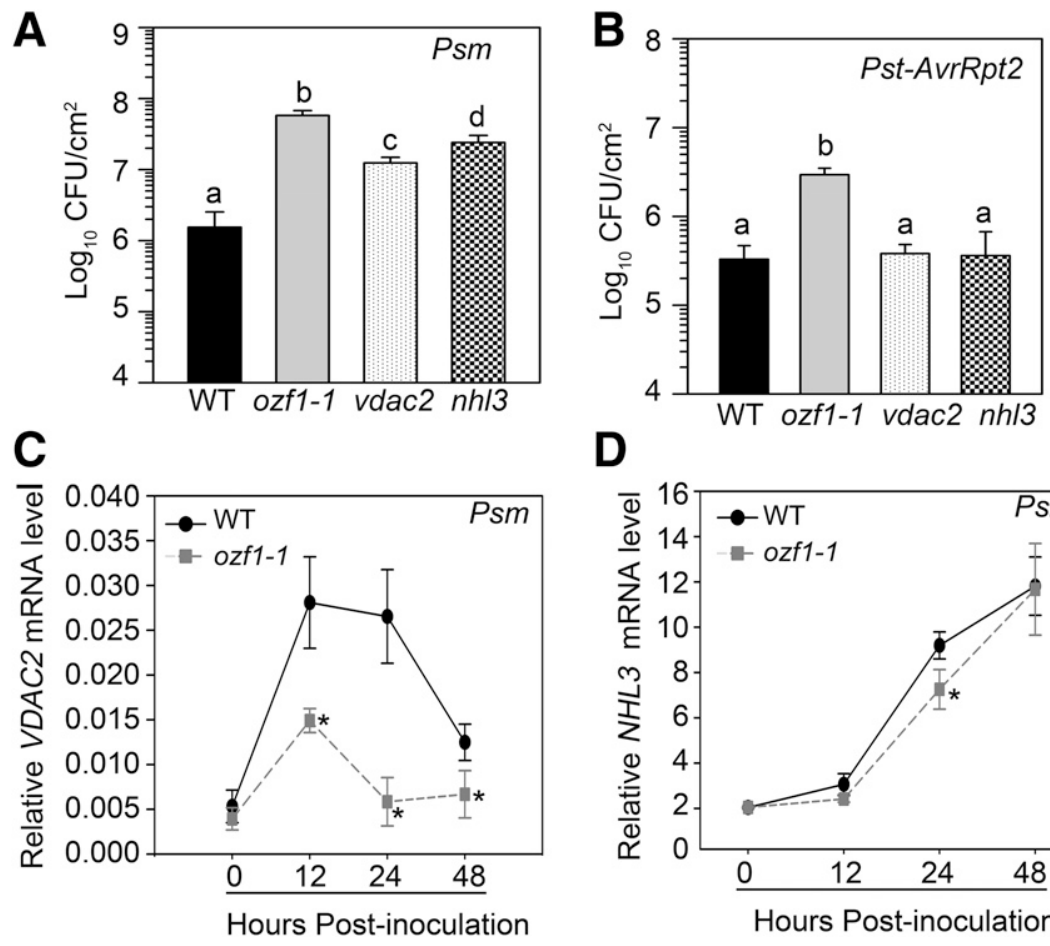

D

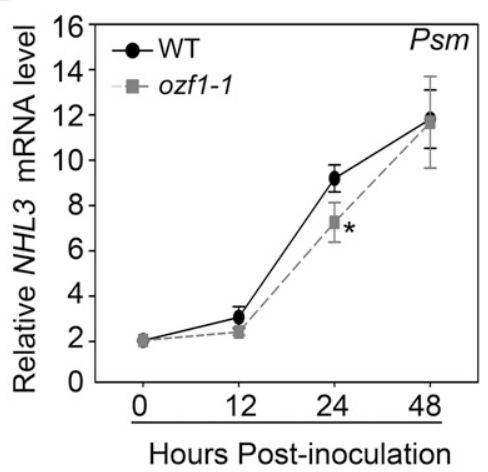

Fig. 7. Role of VDAC2 and NHL3 in defense against bacterial pathogens. A, Pseudomonas syringae pv. maculicola counts at 3 days postinoculation (dpi) B, Pst-AvrRpt 2 counts at 3 dpi. C, VDAC2 mRNA accumulation during pathogenesis. D, NHL3 mRNA accumulation during pathogenesis. Pathogens were inoculated at $5 \times 10^{5} \mathrm{CFU} / \mathrm{ml}$ and bacterial loads were determined at 3 dpi. Each bar represents the mean \pm standard deviation (SD) of four leaf samples, each carrying five leaf discs of $7 \mathrm{~mm}$ in diameter. Different letters above the bars indicate values that are significantly different $(P \leq 0.05)$ from each other, as analyzed by one-way analysis of variance (Holm-Sidak method). In C and D, samples were harvested at the indicated period postinoculation with $P$. syringae pv. maculicola. Transcript accumulation was determined by qPCR. Each point in line plot indicates mean $\pm \operatorname{SD}(n=3)$. Asterisks $(*)$ indicate the values that are significantly different $(P \leq 0.05)$ from wild-type (WT) plants for that specific timepoint. Experiments were repeated two times with similar results. 
mutation was identified by PCR amplification. For $n p r l-2$ identification, we developed a pair of primers for which the PCR amplicon from WT plant gets digested at two positions by BsmI enzyme but at only one in the nprl-2 plant. AtOZF1 overexpressing plants were generated by an Agrobacterium tumefaciens (C58 strain)-mediated floral-dip transformation method. Coding sequences of AtOZF1 was cloned into the binary vector pCXSNHA (Chen et al. 2009) as N-terminal fusion with the HA tag. Transgenic plants were confirmed by reverse transcription (RT)-PCR and Western blot. Arabidopsis plants were grown in an environmentally controlled growth chamber at $22^{\circ} \mathrm{C}$ and $60 \%$ relative humidity, with a 12 -h light and 12 -h dark cycle (Singh et al. 2013). N. benthamiana plants were grown on garden soil at $25^{\circ} \mathrm{C}$ temperature in the glass house.

\section{Pathogen inoculation, SA, and flg22 treatment.}

Pathogen inoculation and determination of bacterial growth were carried out as described previously (Nandi et al. 2003a; Singh et al. 2014). Overnight-grown bacteria were resuspended in $10 \mathrm{mM} \mathrm{MgCl}$ and the suspension was infiltrated into the abaxial sides of leaves with a needleless syringe. Only $10 \mathrm{mM}$ $\mathrm{MgCl}_{2}$ was used as control, whenever required. For SA treatment, 4-week-old plants were sprayed with a solution of SA (Sigma-Aldrich, St. Louis) made in distilled water or only water as the control, and plants were covered overnight with a plastic dome. For flg22 treatment, leaves were infiltrated with either $1 \mu \mu \mathrm{M}$ solution flg22 (Genscript) made in water or only water as control, and plants were covered with a plastic dome for $10 \mathrm{~h}$ before collecting samples for callose deposition study.

\section{Ion-leakage experiment.}

Ion-leakage experiments were performed as described earlier (Bhattacharjee et al. 2017; Roy and Nandi 2017). A suspension of Avr-Pst (at $1 \times 10^{7} \mathrm{CFU} / \mathrm{ml}$ in $10 \mathrm{mM} \mathrm{MgCl} 2$ ) was pressure infiltrated in the abaxial side of fully grown leaves. The control set received only $10 \mathrm{mM} \mathrm{MgCl}_{2}$. Leaf discs of $5 \mathrm{~mm}$ in diameter were taken out immediately after inoculation, were briefly washed with sterile water, and were floated on distilled water in a 6-well plate. We used seven leaf discs per $5 \mathrm{ml}$ of water. The electrical conductivity (microsiemens per centimeter) measured immediately after floating leaf discs was taken as the 0 - $\mathrm{h}$ reading. The floated leaves were incubated in the dark inside the growth chamber for $6 \mathrm{~h}$ and were then transferred to light, after which electrical conductivity readings were taken at 2-h intervals. After completion of the experiment, the liquid, along with the leaf discs, was transferred to 50-ml falcon tubes and was autoclaved, to liberate the entire cellular contents. The electrical conductivity after autoclaving was taken as $100 \%$ ion leakage, and the readings at other timepoints were expressed as the percentage of total ion leakage.

\section{SA estimation.}

Total SA and SAG levels were determined by HPLC (Agilent 1220 LC), as described previously (Singh et al. 2013), with minor modifications. In brief, total SA and SAG was extracted from $200 \mathrm{mg}$ of leaf samples and was dissolved separately in $200 \mu \mathrm{l}$ HPLC running buffer (0.2 M NaOAc, pH 5.2, and $10 \%$ methanol). Using an autosampler, $100 \mu \mathrm{l}$ was loaded into the column $(5 \mu \mathrm{m}$ C-18 reverse-phase $4.6 \mathrm{~mm} \times 150 \mathrm{~mm})$. HPLC was run at $30^{\circ} \mathrm{C}$ with a flow rate of $0.8 \mathrm{ml} / \mathrm{min}$.

\section{RNA extraction and gene expression analyses.}

Isolation of total RNA and cDNA synthesis was done as described earlier (Giri et al. 2017). For Northern blot, total RNA (approximately $6 \mu \mathrm{g}$ ) was separated on agarose gel, was transferred to nylon membrane, and was hybridized with radio- labeled probes for Northern blot analysis (Nandi et al. 2003b, 2004). For qPCR analysis, cDNA was prepared from $1 \mu \mathrm{g}$ of total RNA, using a kit (Bio-Rad) per the manufacturer's protocol. RT-qPCR was done, using $50 \mathrm{ng}$ of cDNA and power SYBR green master mix (Applied Biosystem) in an ABIPRISM 7500 FAST sequence detector, and was analyzed by the system-given software. Typically, each set contained three biological replicates and qPCR was carried out by taking two technical replicates of each cDNA samples. Average of two technical replicates was taken as the value of that biological replicate. Normalization with ACTIN2 (At3g18780) and TUB2 (At5g62690) and primer efficiency calculation was done as described earlier (Giri et al. 2017). Statistical analysis was carried out using $\log _{10}$-transformed values of expression level.

\section{DAB staining and callose deposition.}

DAB staining for ROS detection was carried out as described previously (Roy and Nandi 2017). In brief, leaves were detached along with the petiole and were floated in distilled water overnight. The next day, water was replaced by Pst-AvrRpt2 (a concentration of $10^{8}$ cells per milliliter suspended in $10 \mathrm{mM}$ $\mathrm{MgCl}_{2}$ ) or $10 \mathrm{mM} \mathrm{MgCl}$. After $3 \mathrm{~h}$, the liquid was replaced with DAB solution ( $1 \mathrm{mg} / \mathrm{ml}$ in $10 \mathrm{mM} \mathrm{Na} 2 \mathrm{HPO} 4)$ and vacuum ( $-5 \mathrm{~mm} \mathrm{Hg}$ pressure) was applied for $5 \mathrm{~min}$. The color was developed by slow shaking for 4 to $5 \mathrm{~h}$ at room temperature and was washed with destaining solution (ethanol/acetic acid/glycerol, $3: 1: 1)$. For callose deposition studies, flg22 or pathogen-treated leaves were detached and were incubated with $95 \%$ ethanol overnight for removing chlorophyll. The leaves were washed three times with water and were stained with $0.01 \%$ aniline blue (in $1.5 \mathrm{mM} \mathrm{Na}_{2} \mathrm{HPO} 4$ buffer, $\mathrm{pH} 9.0$ ) for $10 \mathrm{~h}$, before observing
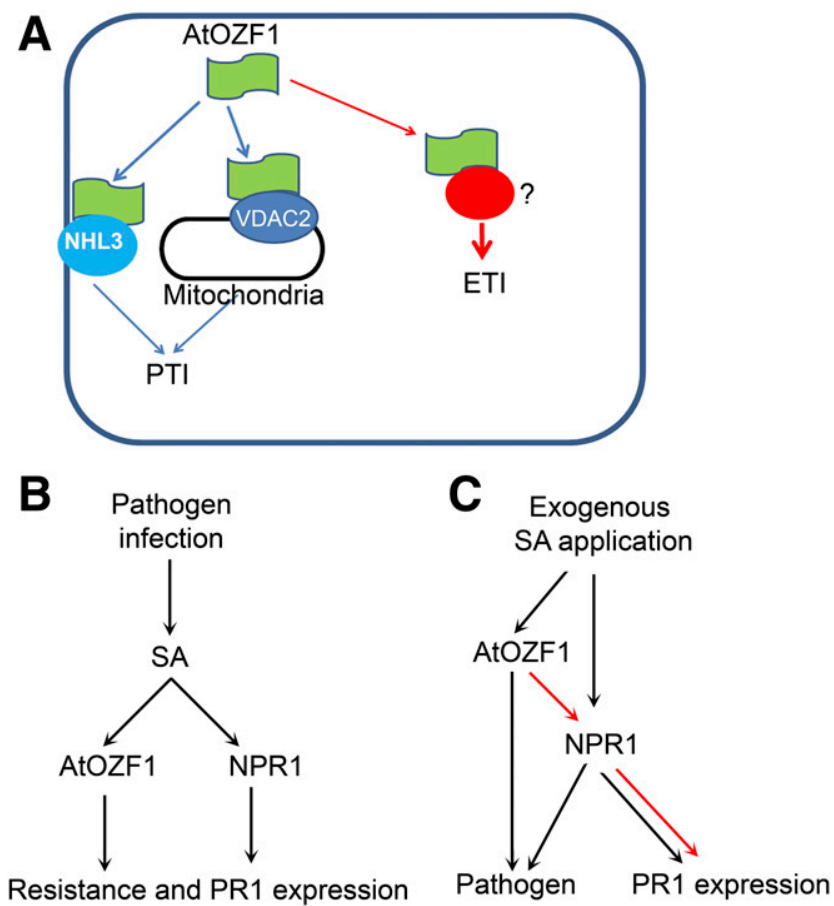

Fig. 8. Models depicting the role of AtOZF1 in plant defense. A, Role of AtOZF1 in pathogen-associated molecular pattern- and effector-triggered immunity (PTI and ETI, respectively). AtOZF1 interacts with VDAC2 and NHL3. Both proteins influence PTI. AtOZF1 also may interact with some other factor (?) for influencing ETI. B, AtOZF1 and NPR1 function in parallel pathways for mounting defense against pathogens and for pathogen-induced PRI expression. C, Exogenous salicylic acid (SA) treatment shows both NPR1-dependent and -independent mechanisms of defense and PR1 expression. 
under a microscope. The amount of callose per observation field $\left(0.04 \mathrm{~mm}^{2}\right)$ was calculated by the imageJ software.

\section{Screening of Arabidopsis cDNA library through a yeast-two-hybrid assay.}

The full-length coding sequence of AtOZF1 was cloned in bait expression vector pGBKT7 (Clonetech). An Arabidopsis normalized cDNA library prepared in pGADT7 vector (Clonetech) was used for screening AtOZF1-interacting factors, following manufacturer's protocol and as described earlier (Banday and Nandi 2017). The yeast clones or transformants were selected on synthetic defined medium lacking Trp, Ura, His, and Ade. Plasmids were isolated from yeast cells and were transformed into Escherichia coli DH5 . For each interacting clone, the bacterial plasmid was isolated and a yeast-two-hybrid assay was repeated. During this step, pGADT7-T and pGBKT7-P53 expressing plasmids DNAs were used as positive control and individual vectors were used as negative control. The yeast transformants were serially diluted before plating in quadruple dropout medium. We selected only the clones that showed interaction strength equal to or more than the positive control. The plasmid DNA was sequenced to get the gene identity.

\section{BiFC and transient expression studies.}

BiFC assay was performed after cloning AtOZF1 and its interacting partners in $\operatorname{PSPYNE}(\mathrm{R}) 173$ and $\operatorname{pSPYCE}(\mathrm{M})$ vectors for generating $\mathrm{N}$ - and C-terminal parts of YFP fused proteins respectively (Waadt et al. 2008). Overnight-grown A. tumefaciens (strain C58) culture having BiFC constructs were expressed in onion cells as described previously (Waadt et al. 2008). For transient expression in N. benthamiana, fully grown leaves of 5 to 6 week-old were coinfiltrated with A.tumefaciens carrying the BiFC construct and HcPro for RNAi suppression constructs (del Toro et al. 2014) both at 0.5 $\mathrm{OD}_{600}$ suspended in MES (10 mM, pH 5.7), acetosyringone $(100 \mu \mathrm{M})$ and MS (0.4\%, Sigma Cat \# M5519).

\section{CoIP.}

CoIP was done as described by Chinchilla et al. (2007), with some modifications. About $1 \mathrm{~g}$ of leaf tissue was frozen in liquid $\mathrm{N}_{2}$ and total protein was extracted by mortar pestle in $2.5 \mathrm{ml}$ of extraction buffer (50 mM,Tris-Cl, pH 8.0, $150 \mathrm{~mm}$ $\mathrm{NaCl}, 10 \%$ [wt/vol] glycerol, $1 \%$ [vol/vol] NonidetP-40, $0.5 \%$ [wt/vol] sodium deoxycholate, and protease inhibitor [Sigma]) The extracted protein was incubated overnight at $4^{\circ} \mathrm{C}$, with protein A-agarose beads (Invitrogen) and anti-HA (Abcam) or anti- Myc (AbCam) antibodies. The beads were collected and were washed three times with ice-cold extraction buffer and once with $50 \mathrm{mM}$ Tris- $\mathrm{HCl}, \mathrm{pH} 7.5$. Finally, elution was done by heating for $10 \mathrm{~min}$ at $50^{\circ} \mathrm{C}$ with and without $100 \mathrm{mM}$ dithiothreitol. Proteins bounded with beads were loaded on sodium dodecyl sulfate-polyacrylamide gels $(12 \%$ [wt/vol]) and were analyzed by immunoblot using anti-Myc or anti-HA antibodies.

\section{ACKNOWLEDGMENT}

We acknowledge Arabidopsis Biological Resource Center, The Ohio University, for providing the T-DNA insertion mutant lines and T. Panwar for confocal microscopic images. This work was supported by the Council for Scientific and Industrial Research (CSIR) (number 38[1358]/13/EMRII) to A. K. K. Nandi; a University Grants Commission (UGC) fellowship to N. Singh and A. Singh, and a CSIR fellowship to S. Swain.

\section{LITERATURE CITED}

Alvarez, M. E., Pennell, R. I., Meijer, P. J., Ishikawa, A., Dixon, R. A., and Lamb, C. 1998. Reactive oxygen intermediates mediate a systemic signal network in the establishment of plant immunity. Cell 92:773-784.
Banday, Z.Z., and Nandi, A.K. 2017. Arabidopsis thaliana GLUTATHIONES-TRANSFERASE THETA 2 interacts with RSI1/FLD to activate systemic acquired resistance. Mol. Plant Pathol. Published online.

Bhattacharjee, L., Singh, D., Gautam, J. K., and Nandi, A. K. 2017. Arabidopsis thaliana serpins AtSRP4 and AtSRP5 negatively regulate stress-induced cell death and effector-triggered immunity induced by bacterial effector AvrRpt2. Physiol. Plant. 159:329-339.

Bigeard, J., Colcombet, J., and Hirt, H. 2015. Signaling mechanisms in pattern-triggered immunity (PTI). Mol. Plant 8:521-539.

Bogamuwa, S. P., and Jang, J. C. 2014. Tandem CCCH zinc finger proteins in plant growth, development and stress response. Plant Cell Physiol. 55: 1367-1375

Boller, T., and He, S. Y. 2009. Innate immunity in plants: An arms race between pattern recognition receptors in plants and effectors in microbia pathogens. Science 324:742-744.

Bolton, M. D. 2009. Primary metabolism and plant defense-fuel for the fire Mol. Plant-Microbe Interact. 22:487-497.

Chaouch, S., Queval, G., and Noctor, G. 2012. AtRbohF is a crucial modulator of defence-associated metabolism and a key actor in the interplay between intracellular oxidative stress and pathogenesis responses in Arabidopsis. Plant J. 69:613-627.

Chen, S., Songkumarn, P., Liu, J., and Wang, G. L. 2009. A versatile zero background T-vector system for gene cloning and functional genomics. Plant Physiol. 150:1111-1121.

Chinchilla, D., Zipfel, C., Robatzek, S., Kemmerling, B., Nürnberger, T., Jones, J. D., Felix, G., and Boller, T. 2007. A flagellin-induced complex of the receptor FLS2 and BAK1 initiates plant defence. Nature 448: 497-500.

Cohn, J., Sessa, G., and Martin, G. B. 2001. Innate immunity in plants. Curr. Opin. Immunol. 13:55-62.

da Cunha, L., McFall, A.J., and Mackey, D. 2006. Innate immunity in plants: A continuum of layered defenses. Microbes Infect. 8:1372-1381.

del Toro, F., Fernández, F. T., Tilsner, J., Wright, K. M., Tenllado, F., Chung, B. N., Praveen, S., and Canto, T. 2014. Potato virus Y HCPro localization at distinct, dynamically related and environment-influenced structures in the cell cytoplasm. Mol. Plant-Microbe Interact. 27:1331-1343.

Delaney, T. P., Uknes, S., Vernooij, B., Friedrich, L., Weymann, K. Negrotto, D., Gaffney, T., Gut-Rella, M., Kessmann, H., Ward, E., and Ryals, J. 1994. A central role of salicylic acid in plant disease resistance. Science 266:1247-1250.

Dong, X. 2004. NPR1, all things considered. Curr. Opin. Plant Biol. 7: 547-552.

Dong, X., Hong, Z., Chatterjee, J., Kim, S., and Verma, D. P. 2008 Expression of callose synthase genes and its connection with $\mathrm{Npr}$ signaling pathway during pathogen infection. Planta 229:87-98.

Galletti, R., Denoux, C., Gambetta, S., Dewdney, J., Ausubel, F. M., De Lorenzo, G., and Ferrari, S. 2008. The AtrbohD-mediated oxidative burst elicited by oligogalacturonides in Arabidopsis is dispensable for the activation of defense responses effective against Botrytis cinerea. Plant Physiol. 148:1695-1706.

Giri, M. K., Singh, N., Banday, Z. Z., Singh, V., Ram, H., Singh, D., Chattopadhyay, S., and Nandi, A. K. 2017. GBF1 differentially regulates CAT2 and PAD4 transcription to promote pathogen defense in Arabidopsis thaliana. Plant J. 91:802-815.

Giri, M. K., Swain, S., Gautam, J. K., Singh, S., Singh, N., Bhattacharjee, L., and Nandi, A. K. 2014. The Arabidopsis thaliana At4g13040 gene, a unique member of the AP2/EREBP family, is a positive regulator for salicylic acid accumulation and basal defense against bacterial pathogens. J. Plant Physiol. 171:860-867.

Glazebrook, J., Rogers, E. E., and Ausubel, F. M. 1996. Isolation of Arabidopsis mutants with enhanced disease susceptibility by direct screening. Genetics 143:973-982.

Godiard, L., Grant, M. R., Dietrich, R. A., Kiedrowski, S., and Dangl, J. L. 1994. Perception and response in plant disease resistance. Curr. Opin. Genet. Dev. 4:662-671.

Guo, Y. H., Yu, Y. P., Wang, D., Wu, C. A., Yang, G. D., Huang, J. G., and Zheng, C. C. 2009. GhZFP1, a novel CCCH-type zinc finger protein from cotton, enhances salt stress tolerance and fungal disease resistance in transgenic tobacco by interacting with GZIRD21A and GZIPR5. New Phytol. 183:62-75.

Heidel, A. J., Clarke, J. D., Antonovics, J., and Dong, X. 2004. Fitness costs of mutations affecting the systemic acquired resistance pathway in Arabidopsis thaliana. Genetics 168:2197-2206.

Herrera-Vásquez, A., Carvallo, L., Blanco, F., Tobar, M., Villarroel-Candia, E., Vicente-Carbajosa, J., Salinas, P., and Holuigue, L. 2015. Transcriptional control of glutaredoxin GRXC9 expression by a salicylic aciddependent and NPR1-independent pathway in Arabidopsis. Plant Mol. Biol. Report. 33:624-637. 
Huang, P., Chung, M. S., Ju, H. W., Na, H. S., Lee, D. J., Cheong, H. S., and Kim, C. S. 2011. Physiological characterization of the Arabidopsis thaliana oxidation-related zinc finger 1, a plasma membrane protein involved in oxidative stress. J. Plant Res. 124:699-705.

Huot, B., Yao, J., Montgomery, B. L., and He, S. Y. 2014. Growth-defense tradeoffs in plants: A balancing act to optimize fitness. Mol. Plant 7: 1267-1287.

Jang, J.-C. 2016. Arginine-rich motif-tandem CCCH zinc finger proteins in plant stress responses and post-transcriptional regulation of gene expression. Plant Sci. 252:118-124.

Jirage, D., Zhou, N., Cooper, B., Clarke, J. D., Dong, X., and Glazebrook, J. 2001. Constitutive salicylic acid-dependent signaling in cprl and cpr6 mutants requires PAD4. Plant J. 26:395-407.

Jones, J. D., and Dangl, J. L. 2006. The plant immune system. Nature 444: 323-329.

Kesarwani, M., Yoo, J., and Dong, X. 2007. Genetic interactions of TGA transcription factors in the regulation of pathogenesis-related genes and disease resistance in Arabidopsis. Plant Physiol. 144:336-346.

Kim, W. C., Kim, J. Y., Ko, J. H., Kang, H., Kim, J., and Han, K. H. 2014. AtC3H14, a plant-specific tandem $\mathrm{CCCH}$ zinc-finger protein, binds to its target mRNAs in a sequence-specific manner and affects cell elongation in Arabidopsis thaliana. Plant J. 80:772-784.

Kusano, T., Tateda, C., Berberich, T., and Takahashi, Y. 2009. Voltagedependent anion channels: Their roles in plant defense and cell death. Plant Cell Rep. 28:1301-1308.

Kwak, J. M., Mori, I. C., Pei, Z. M., Leonhardt, N., Torres, M. A., Dang1, J. L., Bloom, R. E., Bodde, S., Jones, J. D., and Schroeder, J. I. 2003. NADPH oxidase AtrbohD and AtrbohF genes function in ROSdependent ABA signaling in Arabidopsis. EMBO J. 22:2623-2633.

Lee, S. J., Jung, H. J., Kang, H., and Kim, S. Y. 2012. Arabidopsis zinc finger proteins AtC3H49/AtTZF3 and AtC3H20/AtTZF2 are involved in ABA and JA responses. Plant Cell Physiol. 53:673-686.

Li, B., Meng, X., Shan, L., and He, P. 2016. Transcriptional regulation of pattern-triggered immunity in plants. Cell Host Microbe 19:641-650.

Li, X., Clarke, J. D., Zhang, Y., and Dong, X. 2001. Activation of an EDS1mediated $R$-gene pathway in the sncl mutant leads to constitutive, NPR1independent pathogen resistance. Mol. Plant-Microbe Interact. 14:1131-1139.

Liu, P. P., von Dahl, C. C., and Klessig, D. F. 2011. The extent to which methyl salicylate is required for signaling systemic acquired resistance is dependent on exposure to light after infection. Plant Physiol. 157:2216-2226.

Macho, A. P., and Zipfel, C. 2014. Plant PRRs and the activation of innate immune signaling. Mol. Cell 54:263-272.

Morel, J. B., and Dangl, J. L. 1997. The hypersensitive response and the induction of cell death in plants. Cell Death Differ. 4:671-683.

Mou, Z., Fan, W., and Dong, X. 2003. Inducers of plant systemic acquired resistance regulate NPR1 function through redox changes. Cell 113 935-944.

Nandi, A., Kachroo, P., Fukushige, H., Hildebrand, D. F., Klessig, D. F., and Shah, J. 2003a. Ethylene and jasmonic acid signaling affect the NPR1independent expression of defense genes without impacting resistance to Pseudomonas syringae and Peronospora parasitica in the Arabidopsis ssi1 mutant. Mol. Plant-Microbe Interact. 16:588-599.

Nandi, A., Krothapalli, K., Buseman, C. M., Li, M., Welti, R., Enyedi, A., and Shah, J. 2003b. Arabidopsis sfd mutants affect plastidic lipid composition and suppress dwarfing, cell death, and the enhanced disease resistance phenotypes resulting from the deficiency of a fatty acid desaturase. Plant Cell 15:2383-2398.

Nandi, A., Moeder, W., Kachroo, P., Klessig, D. F., and Shah, J. 2005. Arabidopsis ssi2-conferred susceptibility to Botrytis cinerea is dependent on EDS5 and PAD4. Mol. Plant-Microbe Interact. 18:363-370.

Nandi, A., Welti, R., and Shah, J. 2004. The Arabidopsis thaliana dihydroxyacetone phosphate reductase gene SUPPRESSSOR OF FATTY ACID DESATURASE DEFICIENCY1 is required for glycerolipid metabolism and for the activation of systemic acquired resistance. Plant Cell 16 : 465-477.

Nimchuk, Z., Eulgem, T., Holt, B. F., 3rd, and Dangl, J. L. 2003. Recognition and response in the plant immune system. Annu. Rev. Genet. 37: 579-609.

Nürnberger, T., and Scheel, D. 2001. Signal transmission in the plant immune response. Trends Plant Sci. 6:372-379.

Qu, J., Kang, S. G., Wang, W., Musier-Forsyth, K., and Jang, J. C. 2014. The Arabidopsis thaliana tandem zinc finger 1 (AtTZF1) protein in RNA binding and decay. Plant J. 78:452-467.

Roetschi, A., Si-Ammour, A., Belbahri, L., Mauch, F., and Mauch-Mani, B. 2001. Characterization of an Arabidopsis-Phytophthora pathosystem: Resistance requires a functional PAD2 gene and is independent of salicylic acid, ethylene and jasmonic acid signalling. Plant J. 28 293-305.
Roy, S., and Nandi, A. K. 2017. Arabidopsis thaliana methionine sulfoxide reductase B8 influences stress-induced cell death and effector-triggered immunity. Plant Mol. Biol. 93:109-120.

Saleh, A., Withers, J., Mohan, R., Marqués, J., Gu, Y., Yan, S., Zavaliev, R., Nomoto, M., Tada, Y., and Dong, X. 2015. Posttranslational modifications of the master transcriptional regulator NPR1 enable dynamic but tight control of plant immune responses. Cell Host Microbe 18:169-182.

Shah, J., Kachroo, P., and Klessig, D. F. 1999. The Arabidopsis ssil mutation restores pathogenesis-related gene expression in nprl plants and renders defensin gene expression salicylic acid dependent. Plant Cell 11:191-206.

Shah, J., Kachroo, P., Nandi, A., and Klessig, D. F. 2001. A recessive mutation in the Arabidopsis SSI2 gene confers SA- and NPR1independent expression of $P R$ genes and resistance against bacteria and oomycete pathogens. Plant J. 25:563-574.

Singh, V., Roy, S., Giri, M. K., Chaturvedi, R., Chowdhury, Z., Shah, J., and Nandi, A. K. 2013. Arabidopsis thaliana FLOWERING LOCUS D is required for systemic acquired resistance. Mol. Plant-Microbe Interact. 26:1079-1088.

Singh, V., Roy, S., Singh, D., and Nandi, A. K. 2014. Arabidopsis FLOWERING LOCUS D influences systemic-acquired-resistance- induced expression and histone modifications of WRKY genes. J. Biosci. 39:119-126.

Swain, S., Roy, S., Shah, J., Van Wees, S., Pieterse, C. M., and Nandi, A. K. 2011. Arabidopsis thaliana cddl mutant uncouples the constitutive activation of salicylic acid signalling from growth defects. Mol. Plant Pathol. 12:855-865.

Swain, S., Singh, N., and Nandi, A. K. 2015. Identification of plant defence regulators through transcriptional profiling of Arabidopsis thaliana cdd1 mutant. J. Biosci. 40:137-146.

Tateda, C., Watanabe, K., Kusano, T., and Takahashi, Y. 2011. Molecular and genetic characterization of the gene family encoding the voltagedependent anion channel in Arabidopsis. J. Exp. Bot. 62:4773-4785.

Tateda, C., Yamashita, K., Takahashi, F., Kusano, T., and Takahashi, Y 2009. Plant voltage-dependent anion channels are involved in host defense against Pseudomonas cichorii and in Bax-induced cell death Plant Cell Rep. 28:41-51.

Torres, M. A., Dangl, J. L., and Jones, J. D. 2002. Arabidopsis gp91 ${ }^{\text {phox }}$ homologues AtrbohD and AtrbohF are required for accumulation of reactive oxygen intermediates in the plant defense response. Proc. Natl. Acad. Sci. U.S.A. 99:517-522.

Torres, M. A., Jones, J. D., and Dangl, J. L. 2005. Pathogen-induced, NADPH oxidase-derived reactive oxygen intermediates suppress spread of cell death in Arabidopsis thaliana. Nat. Genet. 37:1130-1134.

Tsuda, K., and Katagiri, F. 2010. Comparing signaling mechanisms engaged in pattern-triggered and effector-triggered immunity. Curr Opin. Plant Biol. 13:459-465.

Varet, A., Hause, B., Hause, G., Scheel, D., and Lee, J. 2003. The Arabidopsis NHL3 gene encodes a plasma membrane protein and its overexpression correlates with increased resistance to Pseudomonas syringae pv. tomato DC3000. Plant Physiol. 132:2023-2033.

Varet, A., Parker, J., Tornero, P., Nass, N., Nürnberger, T., Dangl, J. L., Scheel, D., and Lee, J. 2002. NHL25 and NHL3, two NDR1/HIN1-1ike genes in Arabidopsis thaliana with potential role(s) in plant defense. Mol. Plant-Microbe Interact. 15:608-616.

Waadt, R., Schmidt, L. K., Lohse, M., Hashimoto, K., Bock, R., and Kudla, J. 2008. Multicolor bimolecular fluorescence complementation reveals simultaneous formation of alternative CBL/CIPK complexes in planta Plant J. 56:505-516.

Wang, D., Guo, Y., Wu, C., Yang, G., Li, Y., and Zheng, C. 2008. Genomewide analysis of $\mathrm{CCCH}$ zinc finger family in Arabidopsis and rice. BMC Genomics 9:44.

Wildermuth, M. C., Dewdney, J., Wu, G., and Ausubel, F. M. 2001. Isochorismate synthase is required to synthesize salicylic acid for plant defence. Nature 414:562-565.

Yan, S., and Dong, X. 2014. Perception of the plant immune signal salicylic acid. Curr. Opin. Plant Biol. 20:64-68.

Yun, B. W., Feechan, A., Yin, M., Saidi, N. B., Le Bihan, T., Yu, M., Moore, J. W., Kang, J. G., Kwon, E., Spoel, S. H., Pallas, J. A., and Loake, G. J. 2011. S-nitrosylation of NADPH oxidase regulates cell death in plant immunity. Nature 478:264-268.

Zhang, Y., Fan, W., Kinkema, M., Li, X., and Dong, X. 1999. Interaction of NPR1 with basic leucine zipper protein transcription factors that bind sequences required for salicylic acid induction of the $P R-1$ gene. Proc. Natl. Acad. Sci. U.S.A. 96:6523-6528.

Zhou, N., Tootle, T. L., Tsui, F., Klessig, D. F., and Glazebrook, J. 1998. PAD4 functions upstream from salicylic acid to control defense responses in Arabidopsis. Plant Cell 10:1021-1030. 